\title{
Chapter 25 \\ Climate Impact Chains-A Conceptual Modelling Approach for Climate Risk Assessment in the Context of Adaptation Planning
}

\author{
Marc Zebisch, Stefano Terzi, Massimiliano Pittore, Kathrin Renner, \\ and Stefan Schneiderbauer
}

\begin{abstract}
In this paper we present a conceptual framework for a climate risk assessment based on the so-called impact chains. The method follows a general assessment framework consistent with the IPCC AR5 concept on climate risk. This framework has been developed by Eurac Research within the context of various projects with the German Environment Agency and the German Gesellschaft für Internationale Zusammenarbeit (German Corporation for International Cooperation)_GIZ. It has been applied in almost twenty national climate risk assessments worldwide (e.g., Burundi, Bangladesh, Thailand, Vietnam, Madagascar) and has been perceived as (1) an appropriate means for risk analysis, (2) a useful tool for communication of complex cause-effect relationships in climate change impacts and risks, and (3) a great approach to identify entry points for adaptation measures. For an operational risk assessment, impact chains serve as a basis for the selection of appropriate models, indicators or guide more qualitative, expert-based assessments.
\end{abstract}

Keywords Climate risk assessment $\cdot$ Impact chains $\cdot$ Vulnerability $\cdot$ Adaptation

\section{Introduction}

A comprehensive and context-specific climate risk assessment (CRA) is a common and highly recommended step to prepare adaptation planning. Typically, climate risk assessments are built upon information on current climate extremes and scenarios of future climate, an analysis, which other underling factors and trends (ecosystem related, physical, technical, or socio-economic factors) are influencing climate risks

\footnotetext{
M. Zebisch (凶) $\cdot$ S. Terzi $\cdot$ M. Pittore $\cdot$ K. Renner $\cdot$ S. Schneiderbauer Institute for Earth Observation, Eurac Research, Bolzano, Italy

e-mail: marc.zebisch@eurac.edu

S. Schneiderbauer

Institute for Environment and Human Security, United Nations University, GLOMOS

Programme, Bolzano, Italy
} 
in various sectors, an assessment of potential impacts and risks associated with climate extremes and climate change on the respective sectors.

There is no standard way of how to conduct a CRA. However, an ISONorm (ISO/DIS 14091: Adaptation to climate change-Guidelines on vulnerability, impacts and risk assessment) is under preparation (ISO 2020) and containing a selection of suitable tools. National CRAs in Europe follow, in general, the sequence mentioned above, but without a common scheme. An EEA Report (EEA; ETC/CCA 2018) on national climate change vulnerability and risk assessments in Europe provides a good overview on the applied approaches.

Responding to the current lack of frameworks and guidelines for climate risk assessments, Eurac Research has created a conceptual framework called climate impact chains together with various partners. Impact chains were first developed for climate risk assessments in the European Alps (Schneiderbauer et al. 2013; Zebisch et al. 2014), and following applied for the 2 nd national climate risk and vulnerability study for Germany (Buth et al. 2017). Finally, they were transformed into a set of guidelines for climate vulnerability and risk assessment for the German Gesellschaft für Internationale Zusammenarbeit-GIZ (Fritzsche et al. 2015; Zebisch et al. 2017, 2021; Hagenlocher et al. 2018). In the meanwhile, this framework has been applied in almost twenty national climate risk assessments worldwide (e.g., Burundi, Bangladesh, Thailand, Vietnam, Madagascar) and is proposed by the new ISO 14091 as one of the concepts for climate risk assessments in the context of adaptation planning. Moreover, a running JPI Climate project (www.unchain.no) is dealing with the application and improvement of the impact chain concept.

The terminology and concepts of impact chains are referring to the most recent climate risk concept of the IPCC, introduced within the IPCC AR5 in 2015 and further developed for the 2019 IPCC SROC report (Abram et al. 2019). According to the IPCC, climate risks are potential adverse consequences for human or ecological systems caused by climate extremes and climate change. A climate risk (e.g., drought damage in agriculture) results from the interactions between climaterelated hazards (e.g., droughts) with exposure (e.g., agriculture land) and vulnerability (e.g., drought resistance of crops, presence or absence of irrigation) of the social-ecological systems. Adaptation strategies can reduce climate risks, mainly by reducing vulnerabilities, but also by reducing exposure or the climate-hazard itself (see Fig. 25.1).

\section{Methodology-Impact Chains, Operationalisation and Adaptation Planning}

\section{Impact Chains-Conceptual Models of Climate Risks}

Impact chains are conceptual models based on cause-effect chains that include all major factors and processes leading to specific climate risks in a specific context (e.g., 


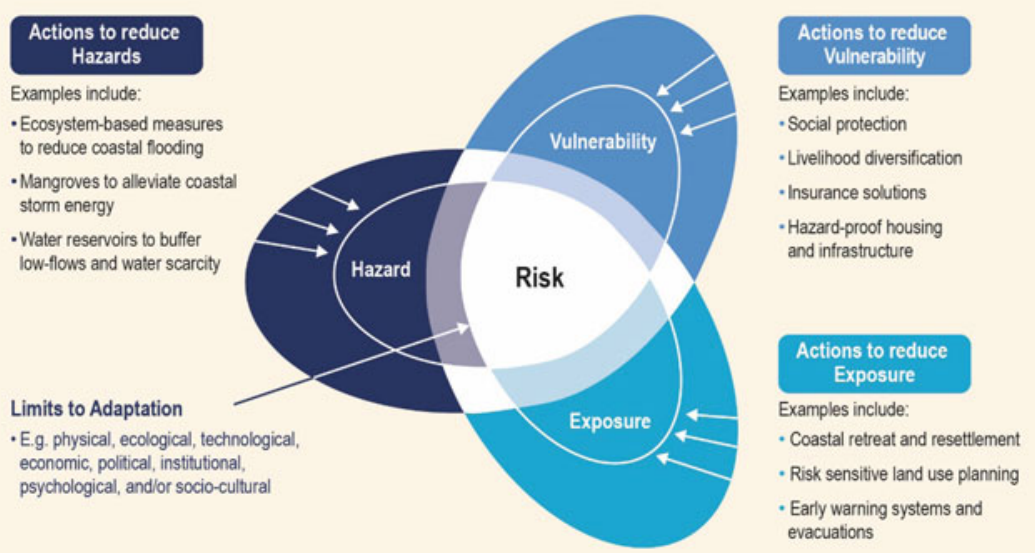

Fig. 25.1 Climate Risk as a function of hazard, vulnerability and exposure-from IPCC SROC (Abram et al. 2019)

regional and/or sectoral). Factors and processes are assigned to the risk components hazard, vulnerability or exposure, while cascading effects are considered as intermediate impacts (Fig. 25.2, left). Impact chains are usually developed in a participatory manner (Fig. 25.2, right) together with stakeholders and experts to create a commonly agreed picture of root-causes for climate risks in a specific context, allow the integration of local data and knowledge (e.g., data from national weather
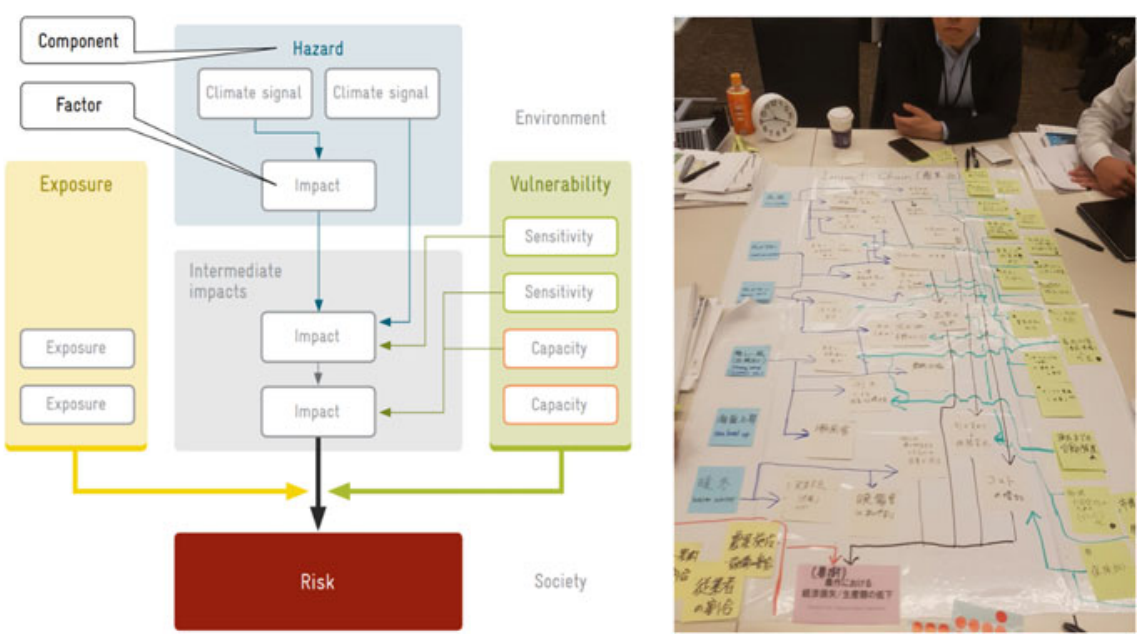

Fig. 25.2 Left: a generic climate impact chain with the risk components hazard, exposure and vulnerability as well as intermediate impacts; right: participatory approach to develop impact chains—case study from Japan (M. Zebisch) 
services, knowledge of local farmers) as well as learnings from the past (e.g., on impacts of past climate events and critical settings and vulnerabilities that increased impacts), consider an adaptation perspective together with adaptation actors (e.g., decision makers from national or local authorities) right from the start.

The development of impact chains takes typically place in a multi-day workshop, ideally combined with field visits both organised as participatory events with engagement of local experts and other stakeholders. This approach often reveals critical elements of a system (vulnerability and/or exposure factors) such as insufficiently maintained flood protection infrastructure or informal settlements in potential flood zones, which would often not be detected by more desk-top and/or model-based approaches.

Impact chains are first built around the current climate risks situation and are than extended through the identification of factors and elements related to a potential future situation. This future situation ideally takes into consideration the projected future climate, but also potential future trends in exposure (e.g., urbanisation leading to a higher exposure values in cities) and vulnerabilities (e.g., an aging population leading to a higher vulnerability of population).

Figure 25.3 shows an example of a simplified impact chain for the 'risk of loss and damage due to floods' in a fictive river catchment in a mountainous environment in South-East Asia. While the hazard-impact-risk relation is often quite straightforward and tangible (e.g., heavy rain events are triggering floods and the related risk of loss and damage due to floods), vulnerability and exposure factors are predominantly complex, strongly context specific and partly intangible. Vulnerability factors include a wide range of issues spanning from natural, ecosystem related parameters and processes (such as a reduced natural retention capacity due to wetland degradation) to more technical parameters (e.g., absence of flood resistant houses) or capacity related parameters (e.g., lack of urban planning). Exposure factors are describing the

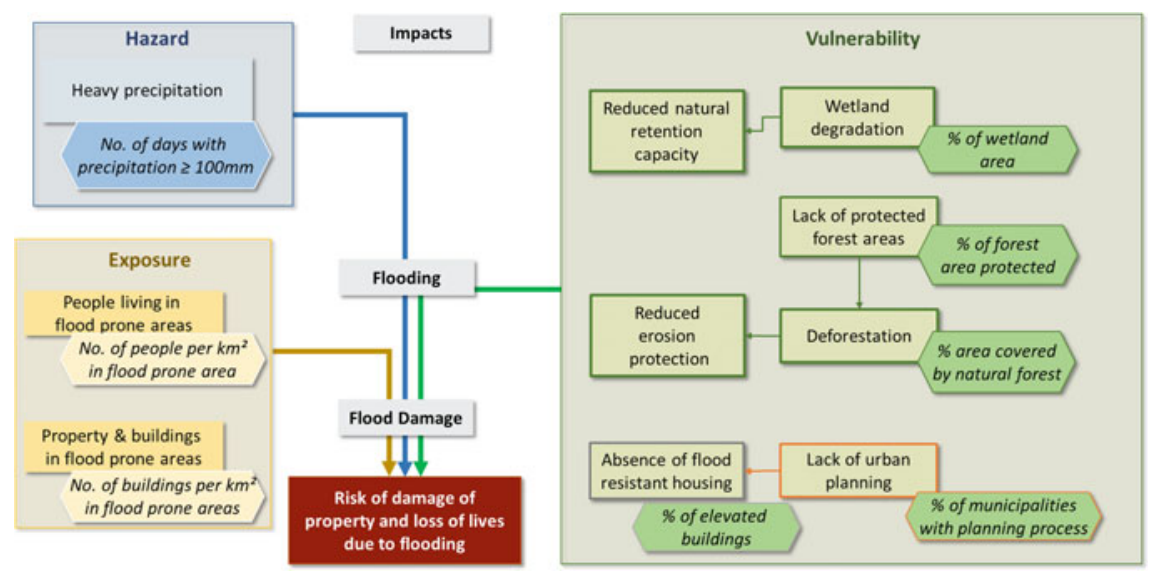

Fig. 25.3 Impact chain for the risk of loss and damage due to floods with single factors (squared boxes) and appropriate indicators for single factors (hexagonal boxes) 
presence, number or density of assets and livelihoods potentially affected by a certain hazard.

\section{Operationalisation-Models, Indicators, Qualitative Approaches}

For an operational risk assessment, impact chains can serve as a backbone for the integration of various methods such as models, indicators or participatory data collection. Often, a combination of these methods is recommended. The general rule is "Take the best you get from and with the resources available". Importantly, the risk assessment should not be driven by data availability only. While for some components of a risk (e.g., information on current and future climate extremes) quantitative data is widely available or physical models exists (e.g., for hydrological risk), for other elements (vulnerability factors, more complex risks) an assessment can only be based on proxy indicators or expert assessments. We strongly recommend not to leave out any relevant risk or underlying process or factor just because respective data is not available. This approach is particularly important within the context of adaptation planning, where a qualitative understanding of specific vulnerabilities is often more important than quantitative, sometimes pseudo-precise, information on hazards or impacts.

The original approach of the Vulnerability Sourcebook (Fritzsche et al. 2015) proposes an indicator-based approach to quantify each risk component and finally the resulting risk. For each of the relevant factors from the impact chains, appropriate indicators are defined (see Fig. 25.3). Indicators are transformed into a common, normative value scheme (e.g., from $0=$ optimal to $5=$ critical), aggregated within risk components, and, finally, into a composite risk indicator for each specific risks. The advantage of such an indicator-based approach is its transparency and the ability to compare different sub-units (e.g., districts) or time slices. However, it requires a data-rich environment and involves a lot of decisions on normalisation, weighting and aggregation. Often, a more comprehensive, narrative aggregation of data and information collected along the factors and elements of an impact chain is a valid alternative.

A typical final result is a report with detailed description of each single climate risk consisting of a mix of narrative information, graphs and maps with information on which underlying factors lead to a specific climate risk in the specific context, which of them are particularly relevant and could be an entry point for adaptation, results from data analysis and models for the specific climate hazard, impact models and indicators, an overall risk assessment (high, medium, low) for the current situation and selected future time slices under different climate scenarios, if possible, on the level of spatial sub-units (e.g., districts or bio-geographical zones), spatial hotspots 
or specific settings that lead to a higher than average risk, uncertainties and confidence levels based on a qualitative assessment of different sources of uncertainty and disagreement.

\section{How Impact Chains Support Adaptation Planning}

Impact chains can foster the discussion on adaptation demand already in an early, qualitative stage of a risk assessment. Particularly, when developing the impact chains with stakeholders and discussing on vulnerability factors ("what makes your system vulnerable against a specific climate hazard?") specific sensitivities (e.g., droughtsensitive crop types) or the lack of technologies as well as capacities (e.g., the lack of an efficient irrigation system, the lack of a hazard zone planning or the lack of an integrated water resource management strategy) immediately pops up (examples of adaptation options for the fictive case in Fig. 25.4. Already during this phase, appropriate measures to tackle these deficits can be discussed and recorded. After the operational risk assessment, more details about critical settings or spatial hotspots are revealed, which allows for a more targeted discussion on adaptation options (e.g., where exactly an adaptation measure must be applied). A reverse discussion (which adaptation measures could be appropriate or have been applied in a similar context in other regions) may help to discover potential vulnerabilities that have been overlooked so far. Involving responsible stakeholders or experts for adaptation measures already in the risk assessment phase guarantees a higher commitment and a smooth and consistent transition from the risk assessment towards the adaptation planning phase.

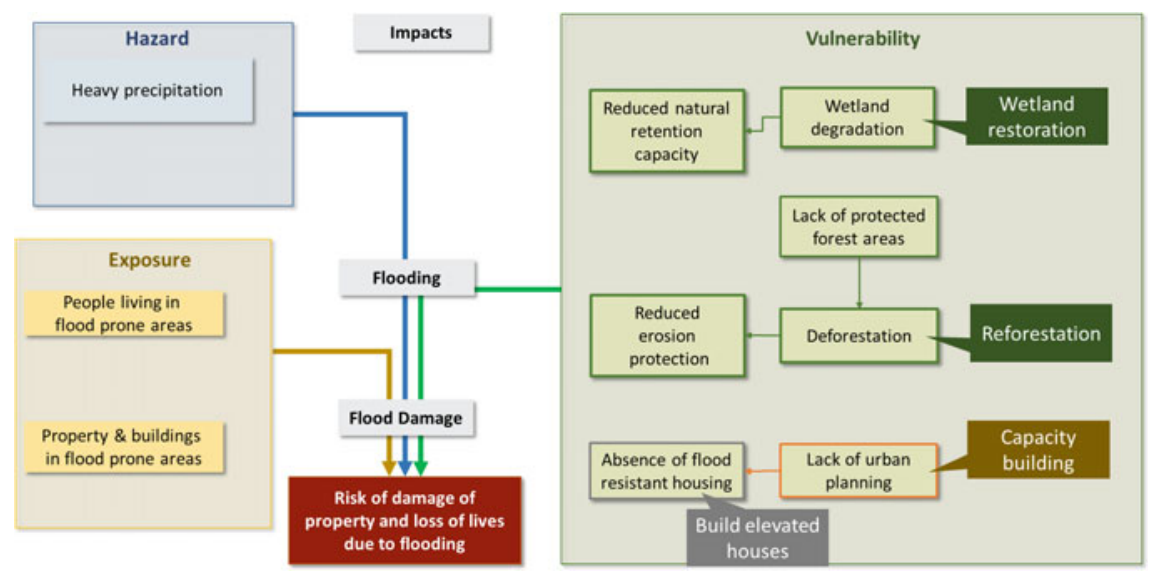

Fig. 25.4 Adaptation options as a result of impact chains development and discussion on vulnerability factors 


\section{Conclusion and Recommendations}

In real-world applications, impact chains have been perceived as a very useful tool for analysis as well as for communication of complex cause-effect relationships in climate change impacts and risks. Particularly, the participatory approach has been highly appreciated in order to obtain a structured and agreed picture of context specific climate risks in-line with the IPCC AR5 climate risk concept. For a successful participatory process, it is important to gather relevant regional/local expertise for the selected climate risks and sectors (examples of such are agriculture, water management and tourism). At the national scale, this could include experts from national environmental ministries and agencies, line ministries and agencies, national statistical offices, national meteorological services, national universities as well as stakeholders from the private sector. All of them might also be data providers and, since data availability is often a bottleneck for the definition and population of indicators, data availability should be discussed with them early in the process.

Amongst the main advantages of impact chains is the possibility to highlight and describe relevant impacting mechanisms related to different hazards on complex and heterogeneous socio-ecological systems, also pinpointing causal relationships and relevant factors over a broad spectrum of vulnerability facets. Modelling such complex relationships requires a hybrid approach (quantitative/qualitative). While data on climate hazards (e.g., drought) is usually available for current and future climate, data on exposure (e.g., population density) or vulnerability is often available only for the current situation or completely missing. For physical factors or processes (e.g., land degradation), analysis from earth observation could be an appropriate approach to gather information on current status and trends. Expert based approaches are often the only solution to describe complex risks but have the disadvantage of a potential bias related to the selection of experts. A challenge related to this hybrid approach is validation. While climate models and some impact models can be validated for the current situation, indicator-based and expert-based approaches are often more hypothesis driven. Options for validation of hybrid and hypothesis driven methods are an interesting field for future research. Another question for future research is to which extend a climate risk assessment could integrate elements of a classical Disaster Risk approach by providing quantitative estimates of expected loss and damage and their likelihood.

Finally, every risk assessment is in the end a value-based approach. Risk depends on priorities, values, targets and normative settings. Therefore, in each risk assessment a discussion on which effects of climate extremes and climate change would fundamentally threaten a system ("high risk") and which effects might be tolerable or are within the coping capacity of a system ("low risk") should be conducted. 


\section{References}

Abram N et al (2019) Framing and context of the report. In: IPCC special report on the ocean and cryosphere in a changing climate', IPCC

Buth M, Kahlenborn W, Greiving S, Fleischhauer M, Zebisch M, Schneiderbauer S, Schauser I (2017) Guidelines for climate impact and vulnerability assessments. Dessau

EEA; ETC/CCA (2018) National climate change vulnerability and risk assessments in Europe, EEA Report No 1/2018. Copenhagen

Fritzsche K, Schneiderbauer S, Bubeck P, Kienberger S, Buth M, Zebisch M, Kahlenborn W (2015) The vulnerability sourcebook. Edited by GIZ - Gesellschaft für internationale Zusammenarbeit. Eschborn. https://www.adaptationcommunity.net/?wpfb_dl=203

Hagenlocher M, Schneiderbauer S, Sebesvari Z, Bertram M, Renner K, Renaud F, Wiley H, Zebisch M (2018) Climate risk assessment for ecosystem-based adaptation - a guidebook for planners and practitioners. Bonn. https://www.adaptationcommunity.net/wp-content/uploads/2018/ 06/giz-eurac-unu-2018-en-guidebook-climate-risk-asessment-eba.pdf

International Organization for Standardization (2020) ISO/DIS 14091 Adaptation to climate change - Guidelines on vulnerability, impacts and risk assessment. Geneva

Schneiderbauer S, Zebisch M, Kass S, Pedoth L (2013) 'Assessment of vulnerability to natural hazards and climate change in mountain environments - examples from the Alpse. In: Birkmann $\mathbf{J}$ (ed) Measuring vulnerability. United University Press

Zebisch M, Schneiderbauer S, Pedoth L (2014) Regional vulnerability assessment in the Alps. In: Prutsch A, McCallum S, Swart R, Grothmann T, Schauser I (eds) Climate change adaptation manual. Lessons learned from European and other industrialized countries. Tayler \& Francis/Routledge

Zebisch M, Schneiderbauer S, Renner K, Below T, Brossmann M, Ederer W, Schwan S (2017) Risk Supplement to the Vulnerability Sourcebook. Guidance on how to apply the Vulnerability Sourcebook's approach with the new IPCC AR5 concept of climate risk'. Bonn. https://www.adaptationcommunity.net/wp-content/uploads/2017/10/GIZ-2017_Risk-Sup plement-to-the-Vulnerability-Sourcebook.pdf

Zebisch M, Schneiderbauer S, Fritzsche K, Bubeck P, Kienberger S, Kahlenborn W, Schwan S, Below T (2021) 'The vulnerability sourcebook and climate impact chains-a standardised framework for a climate vulnerability and risk assessment Vulnerability sourcebook and climate impact c, ahead-of-p(ahead-of-print). https://doi.org/10.1108/IJCCSM-07-2019-0042

Open Access This chapter is licensed under the terms of the Creative Commons Attribution 4.0 International License (http://creativecommons.org/licenses/by/4.0/), which permits use, sharing, adaptation, distribution and reproduction in any medium or format, as long as you give appropriate credit to the original author(s) and the source, provide a link to the Creative Commons license and indicate if changes were made.

The images or other third party material in this chapter are included in the chapter's Creative Commons license, unless indicated otherwise in a credit line to the material. If material is not included in the chapter's Creative Commons license and your intended use is not permitted by statutory regulation or exceeds the permitted use, you will need to obtain permission directly from the copyright holder.

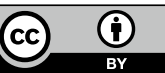

